\title{
Potentials and Challenges of Promoting Bunno Bedelele Zone Major Tourism Destinations, South Western Ethiopia
}

\author{
Habib Bati Geda \\ Department of Ecotourism and Biodiversity conservations \\ Mettu University, P.O.Box ,318, Bedele,Ethiopia
}

\begin{abstract}
Ethiopia in general and Bunno Bedelle Zone in particular, is rich in both natural and cultural tourism resources. Conversely, it's economic, socio-cultural and environmental role is insignificant due to problems mainly related to the lack of infrastructural development and marketing of the destination. In order to make tourism development more sustainable, it is important to look into the problems associated with promoting and marketing of the tourist destinations. Thus, as to achieve the objective of the study a mixed research methodology was implemented. Since the aim of this study was to assess the potentials and Challenges of promoting Bunno Bedelle Zone major tourism destinations site. The research was typically descriptive in nature. In this study, both primary and secondary data was gathered. The data was collected through extensive, questionnaire, interview, focus group discussion, and field observation. The collected data were coded, processed and analyzed with the help of SPSS. The finding of the study demonstrated that the promotional activities of Bunno Bedelle Zone failed to meet their ultimate goal to become an important tourist destination because of limitation in community capacity building in tourism concept, lack of expertise in the area to develop ecotourism and lack of basic infrastructure like absence of adequate transport facilities, communication facilities, health care facilities , accommodation service, Above all, awareness problems, and lack of cooperation between stakeholders aggravated problems which prevent sustainability. To establish the ecotourism and minimizing the challenges of tourist destinations, there should be broader awareness creation program for the wider communities to develop community sense of ownership for their own resource and further investigations is needed to identify and promote the potential tourism resources of the areas.
\end{abstract}

Keywords: Tourism potentials, Promotion, Tourism destinations, Bunno Beddele Zone, Ethiopia.

DOI: $10.7176 /$ JTHS/52-01

Publication date: December $31^{\text {st }} 2020$

\section{INTRODUCTION}

\subsection{Background of the study}

The travel and tourism industry are globally becoming an increasingly expanding area and is the most important economic catalyst in many countries. Over the past six decades, tourism has continued to expand and is, according to the World Tourism Organization (UNWTO, 2015), now one of the largest and fastest growing economic sectors in the world with an estimated number of 1,087 million international tourist arrivals in 2013, with a growth of 5\% over the previous year. International tourist receipts grew to US\$ 1159 billion in 2013. It is also the largest employment generator worldwide with 1 in 11 jobs in the service industries.

Tourism has the potential to contribute significantly to economic growth and development in Africa (Roselyne, 2010). Despite its positive endowment and good growth in tourism over past decade, it remains a sad fact that Africa's tourism potential is underexploited and underdeveloped. Africa's share from total international tourist arrivals and receipts as of 2013 is only 5\% and 3\%, respectively (UNWTO, 2015). The situation in Ethiopia is even worse. Even though, its tourism potential is diversified and immense, which comprises well preserved natural attractions, magnificent historical traditions, an attractive cultural diversity of more than 80 nations and nationalities, the country is still one of the most poorly performing countries in terms of tourist arrivals and receipts (MoCT, 2010). For example, the total number of tourist arrivals in Ethiopia in 2012 was 596,000 which is more than four times smaller than the number in neighboring Kenya, 1,619,000 (UNWTO, 2015).

The travel and tourism industry is a very competitive market at the international level, where only the bestmanaged and marketed enterprises and destinations are likely to benefit. Since there is a huge and steadily rising number of international tourist destinations, which means destination choice available for tourists are continually expanding, there is fierce competition in which some 200 nations are "clamoring for a share of the tourist's heart, mind and wallet" (Sharpley and Telfer, 2002). The promotion of tourism resource is an important approach for many developing countries to influence tourists' destination preference (Ghosh, 2005). It also guarantees the destination image improvement in terms of economic viability, socio-cultural and environmental sustainability. Most tourism destinations of Ethiopia in general and Bunno Bedelle Zone in particular, are not properly marketed and promoted (Ayalew, 2009). Marketing and promoting tourism destinations of the country can help to increase international and domestic tourist inflows which invariably lead to higher tourist receipt. Consequently, this enables the government of Ethiopia to achieve the Growth and Transformation Plan (GTP) for addressing poverty and its goal to become one of the five best tourist destinations in Africa by 2020. 
Although Bunno Bedelle Zone, and Oromia Region in Ethiopia, is rich in tourism potential many more, its economic impact is insignificant. Moreover, due consideration has not been given to marketing and promoting tourism destinations of Bunno Bedelle Zone by National and regional tourism bureaus and destination administrators. Above all, there is lack of studies concerning challenges in promoting tourist destinations of study area. Thus, this study was proposed to find out the potentials and what the actual challenges are that affect tourism destination marketing and promotion activities of the zone administrative bodies and also to unpack the current trend.

\subsection{Objectives of the study}

1.2.1 General Objectives

To assess the Potentials and challenges of promoting Bunno Bedelele Zone major tourism destinations.

\subsubsection{Specific Objectives}

$\checkmark$ To assess the current tourism potentials of Bunno Bedele Zone.

$\checkmark$ To look into the problems associated with promoting and marketing major Bunno Bedele Zone tourism destinations.

$\checkmark$ To identify the appropriate tools for marketing and promotion of Bale Zone major tourism resources.

\subsection{Significance of the Study}

This study is expected to have significance as it contributes by showing the current tourism destinations and marketing problems, and also by suggesting appropriate tourism promotion approaches in the study area which will be helpful for Culture and Tourism Bureaus at different levels to revise their policy so as to be more effective. Likewise, the findings of the research will have essential roles for policy formulation and decision making at all levels (such as, Regional, Zonal, Woreda, Kebele and grass root level of the community) to have appropriate marketing strategies. Since the research results will be forwarded to the Culture and Tourism Offices and other development agents, it will improve the knowledge and attitude of people about the tools that are suitable for marketing the suggest needed tourism resources.

\section{MATERIALS AND METHODS}

\subsection{Description of the study area.}

3.1.1 LOCATION.

The study was conducted at Bunno Bedelle zone, western of oromia region. Buno Bedele zone is one of the newly emerged zone with ten district in south western part of oromia regional states in 2008E.C.It is bordered to the south by jimma zone, to the east by East wollega zone, to the west by Illu Aba Bor Zone and to the north by West wollega zone. The capital city of the zone is Bedelle town and it is located 480km away from Addis Ababa. The zone has good climatic conditions and evergreen throught the year. 


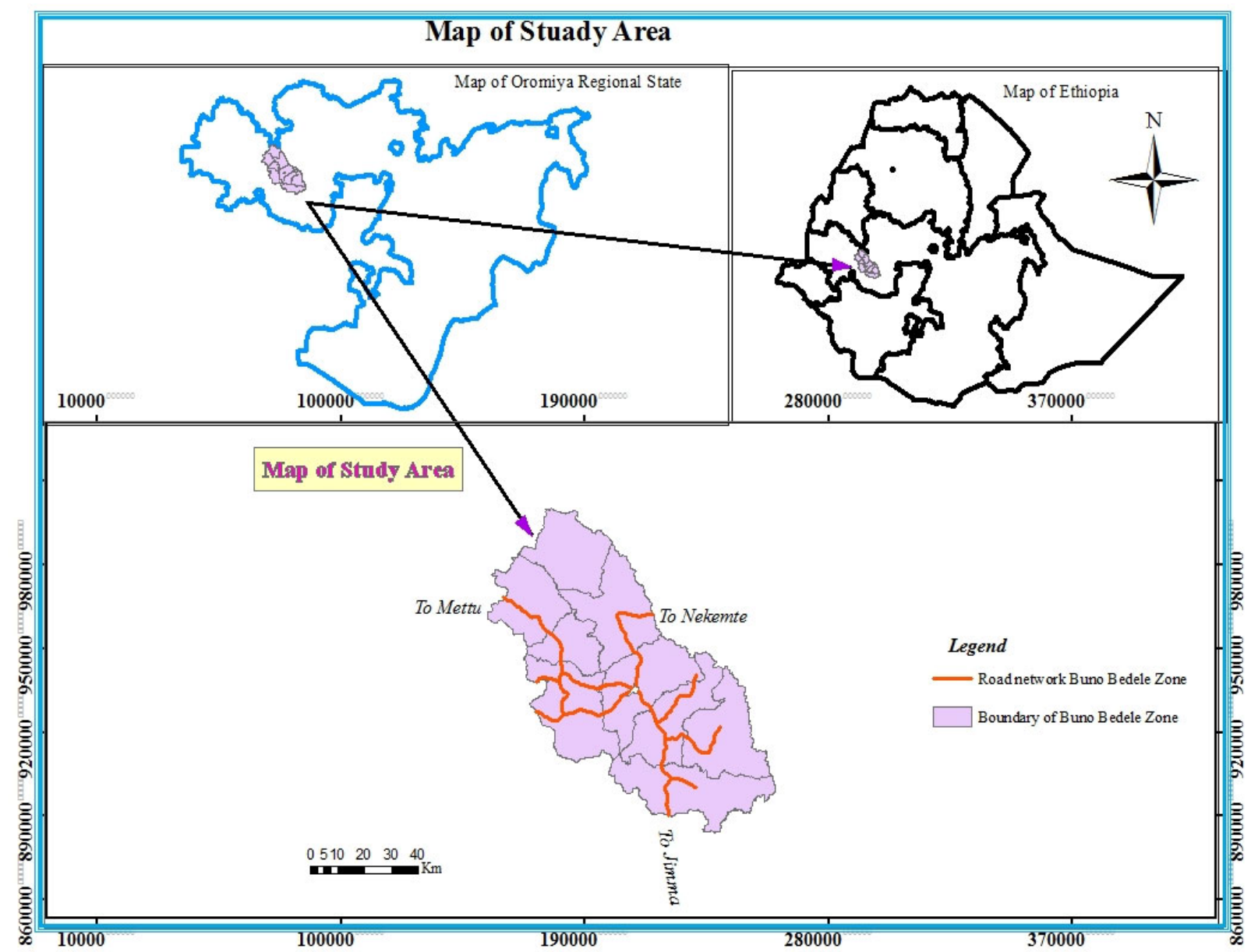

Figure1: Map of study area.

\subsubsection{Socio-economic conditions of community}

The community practice mixed farming mode of life. Different kinds of crops, vegetables, livestock, oil crops and coffee etc. are under production in the woreda. Coffee and Khat, teff and maize are an important cash crop of the area.

\subsection{Research Methods}

\subsubsection{Study site selections and Sampling design}

The rational for selecting Bunno Bedelle Zone was the presence of various natural and cultural potential resource for ecotourism development .Purposive sampling techniques was used to select target populations from officials working in the Zone and Woredas Culture and Tourism offices, none governmental development bodies, local communities elders, and destination managers of the study areas for the interview and FGDs. Participants were selected based on the experiences, skills and knowledge of experts on the theme of the research. 171 respondents were selected among 300 target populations based on the formula of (Israel, 1992).

where:

$$
n=\frac{N}{1+N(e) 2}=\frac{300}{1+300(0.05) 2}=171
$$

$\mathrm{n}=$ sample size required

$\mathrm{N}=$ number of people in the population

$\mathrm{e}=$ the precision level which is $=( \pm 5 \%)$

Where Confidence Level is $95 \%$ at $\mathrm{P}= \pm 5$ (maximum variability)

\subsubsection{Methods of Data Collections}

To undertake this study, both primary and secondary data were used by employing both qualitative and quantitative. The primary data was collected using structured questionnaire that was administered by the researcher. The questionnaire was pre-tested and a necessary correction was made before actual use. During interview, the researcher provided enough information about the objectives of the study to avoid potential bias from the respondents in responding to questions. Secondary data were collected from relevant sources such as from bureau 
of Oromia Forest and wildlife enterprise of the Bunno Bedelle Zone, Ministry of Culture and Tourism bureau of the zone as well the woreda, in addition secondary data from literature review and previously published research and articles was also used.

\subsubsection{Interview}

Interview were conducted with Community representatives, staff members of cultural and tourism bureau and Oromia forest and wildlife enterprise of the zone and woredas. To do these a list of questions was prepared and respondents were interviewed to forward their ideas, opinions, feelings and knowledge regarding the potentials and obstacles to promote tourism potentials of the destinations., role of community to conserve biodiversity and their responsibility to develop ecotourism in the area were part of interview questions.

\subsubsection{Focused group discussion}

Focus group discussions were carried out with local elders, community leaders, including individuals who have adequate knowledge of tourism potentials of the areas). The issues discussed include the potential resource for ecotourism and challenges of promoting ecotourism potentials of the areas., role of government and community to develop ecotourism in the study area, ,weather community has been taken any training concerning awareness creations program and biodiversity issues in general and ecotourism in particular were some of the points discussed with the community during study period.

\subsubsection{Questionnaire surveys}

Questionnaire survey was carried out with respondents to gather data on socioeconomic characteristics, potential tourism resource of the area and challenges that hinders to promote potential tourism resources of destination site and appropriate tools to promote tourism destination site of the areas.

\subsubsection{Key informants' interview}

Key informant interview were carried out with 15 respondents purposely taken through snowball methods these were, , community leader, manager of Oromia forest and wild life enterprise, staff member of Oromia forest and wild life enterprise, manager of tourism bureau of zone and to collect reliable information about potential resource of Bunno Bedele Zone and different water body available in the area, challenges limit to promote ecotourism destinations of the area and appropriate tools used to promote tourism destinations of the area were the questions asked .

\subsubsection{Field observation}

Observation was the main instrument of data collection applied during area visitation to observe the condition of biodiversity, potential resource for ecotourism and challenges of promoting tourism destinations of the area. In addition, infrastructure facilities and life style of the local people nearby the destinations site was observed during area visitations. To capture information, Note book and photo camera were used.

\subsection{METHODS OF DATA ANALYSIS}

Data analyses were done both quantitatively and qualitatively. The data gathered using questionnaire was first arranged and organized in tables and changed into frequency and percentage, and then it is classified and tabulated., SPSS statistics version 20 was used for performing percentage, frequency, graphs (bar charts) to show results. Text explanations and descriptions were used in case of qualitative data analysis. Data collected through interview were analyzed systematically based on the techniques of listening and transcription, reduction to units of relevant meaning and summarization. Data collected through focused group discussion was critically analyzed by using the guidelines which was used for analyzing interview responses. Data collected through field observation was analyzed in the form of text.

\section{RESULT AND DISCUSSIONS}

\subsection{Source of income.}

In order to identify the major source of income, basic data were collected from the respondents. Based on their response crop farming, livestock rearing, mixed farming (both livestock rearing and crop farming) and other income generating activities like handcraft and beekeeping activities are the major source of their income as indicated in (Figure2) 


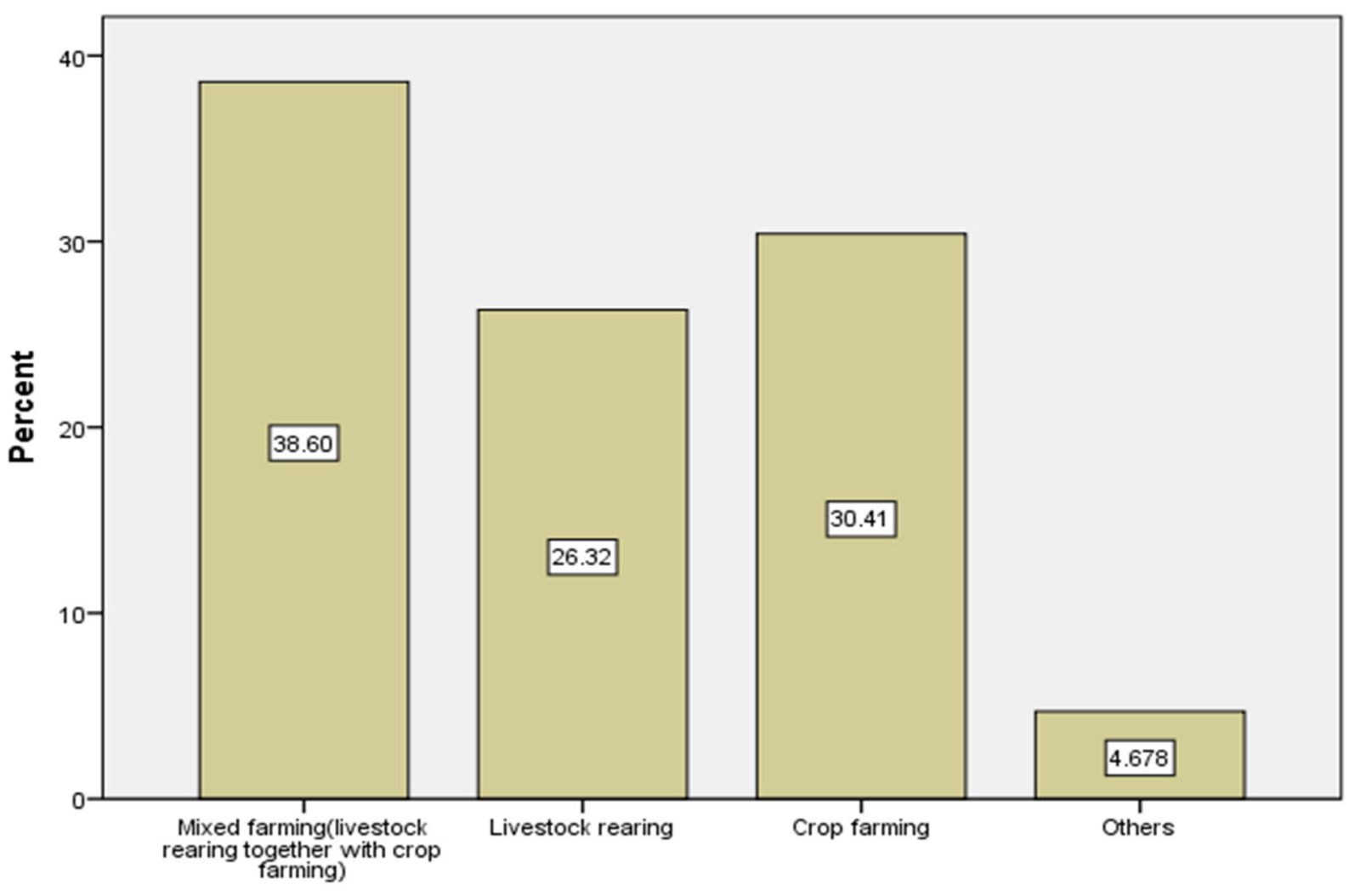

\section{Community Source of income}

Figure2: Income source of community

Concerning community source of income $38.60 \%$ respondent mentioned that mixed farming (both crop farming and livestock rearing) is their income generating activity and crop farming accounts $30.41 \%$ and the rest of them practice livestock rearing and other income generating activities like handicrafts and bee keeping activities contributed $26.32 \%$ and $4.67 \%$ respectively. Human population increase, need of grazing land and agricultural expansion will negatively affect the tourism destinations of the areas unless other alternative income generating activity like ecotourism is established in the area, the potential resource of the area could be destructed by over grazing, settlement, and farm land expansion.

\subsection{Natural resource for ecotourism development in Bunno Beddele Zone.}

$\checkmark$ The area is also drained by different seasonal (intermittent) and principal rivers of high potential for varieties of economic activities. For instance, the principal rivers that constantly flow throughout the year like:

$\checkmark$ Dabena, Didesa, and other principal rivers that have high potential for transportation and large-scale irrigation in their lowland areas and potential source of fish species, scenic mountains that is having good climatic conditions and hot spring that is used to cure desease. This indicated that Presence of this natural resource is the base for ecotourism development .However it need effective management and promotions (Figure3).

Aba Bekele water fall: According to focus group discussions Dega woreda is full of attractive natural and cultural tourist attraction site. Some of tourist attraction sites in the woreda are. , Bala Dagna Cave, Bokicha Mountain, Sida Aba Café, (Cultural \& Historical sites) and Sida Aba mathi, Meko Mountain, Tabala Kunbure (Hot Springs). According to focus group discusions and sampled respondents response all of these centers are natural and there were no any facilities around these places. The absence of facilities, the absence of graveled road construction, and luck of enough budgets, water pipe line and low awareness's the district lack of budget from the tourists are some of the obstacles that hinders the development of ecotourism in the area(fig3). 


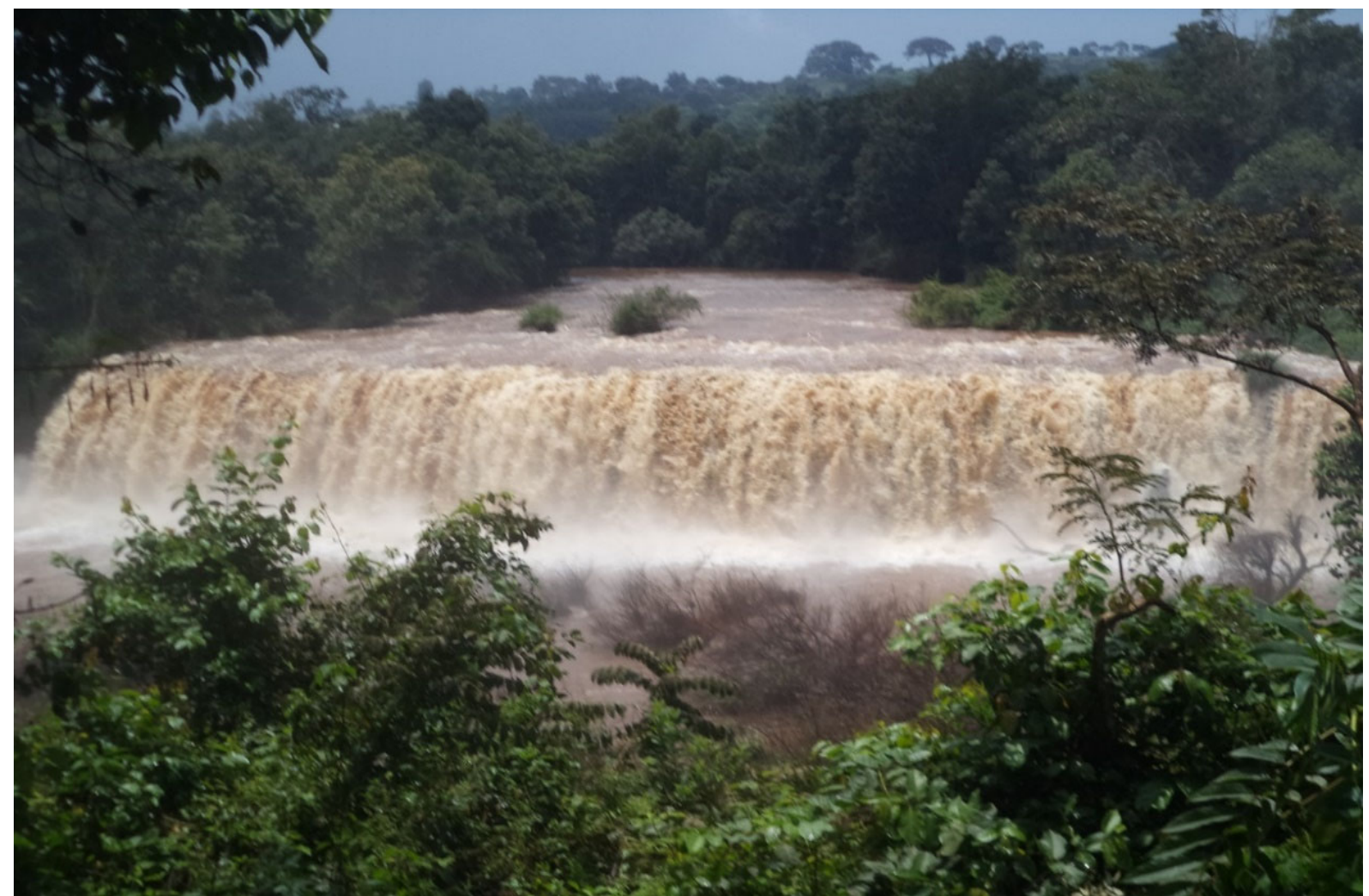

Figure3: Aba Bakale waterfall

Dangiwaj Water fall

Based on focus group discussions and researcher field observations Dangiwaj water fall is one of the tourist attractions of natural cave that is found in the gechi woredas of Bunno Bedelle Zone. The woreda has one natural cave site attraction and three natural forest tourist attraction centers(fig4) .

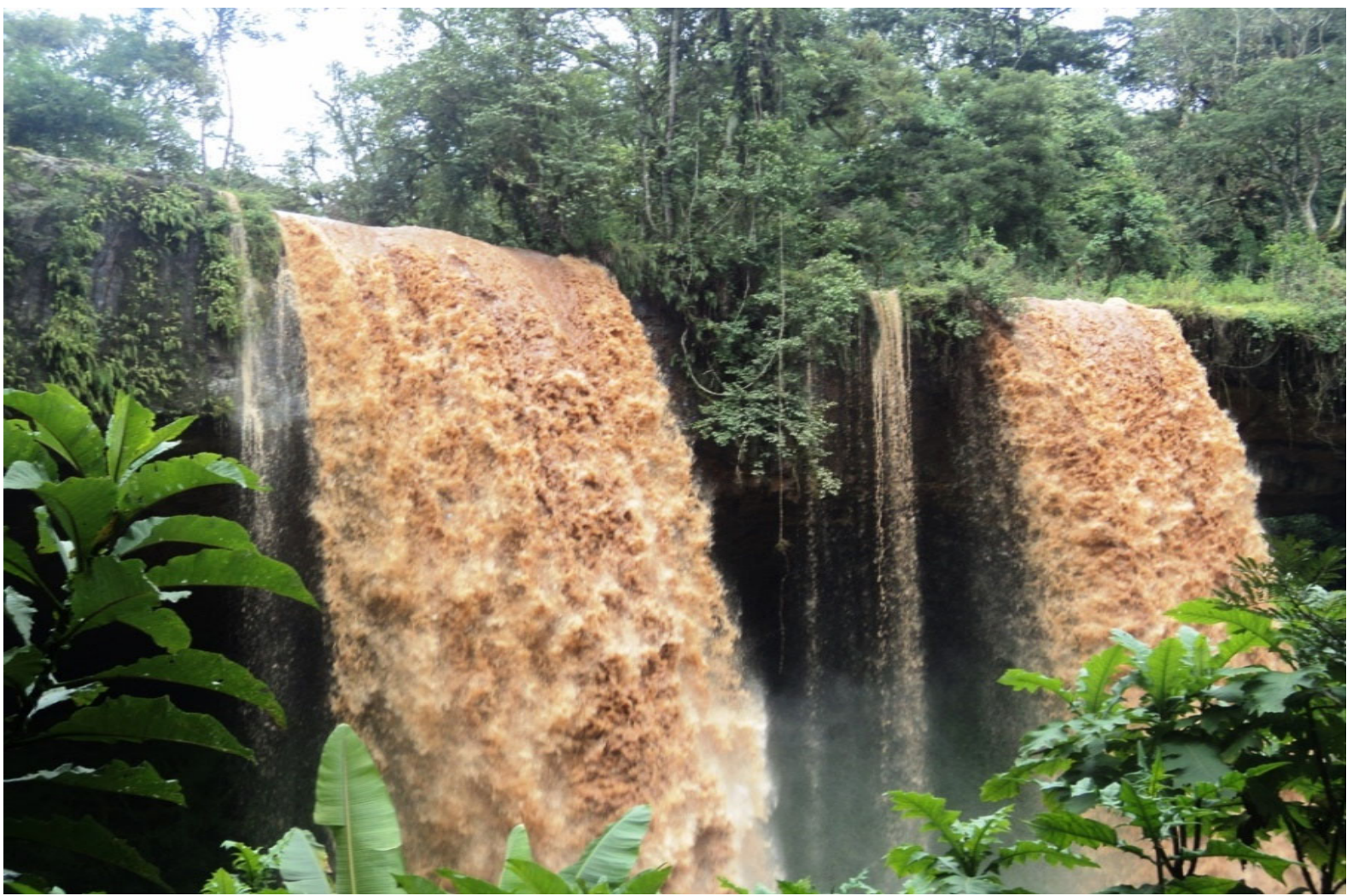

Figure4: Dangiwaj Water fall 


\section{Haro Aba Diko Controlled Hunting area forest in Dabo Hana woreda}

Tourism is an industry that brings about both direct and indirect economic and social benefits, and consequently supports other economic sectors. Despite the enormous tourism potential in the woreda much was not developed and well recognized yet in the way it contributes to the overall regional development.

The dense natural forest found in Dabo hana woreda is an important potential tourism resources of the areas. The forest consists of old and big natural trees. According to focus group discussions this forest extends up to mako woreda and consists of various flora and founa that is source of tourist attractions. some of the founa that are found in this forest area are: African Buffalo (Syncerus caffer), Bush Pig, ( Potamochoerus larvatus) Black and white monkey(Colobus guereza), Common bush Buck(Tragelaphus scriptus), Water Buck(Kobus ellipsiprymnus ) Plain Zebra (Equus quagga,) Blue monkey (Cercopiticus mitis) and vegetations ranges from herbaceous to tree species.Based on respondents and key informants interviewYako Cave and Chayi Cave are another historical site that was found in the woreda including Aba café one of the tourist cultural attractions (fig $5)$.

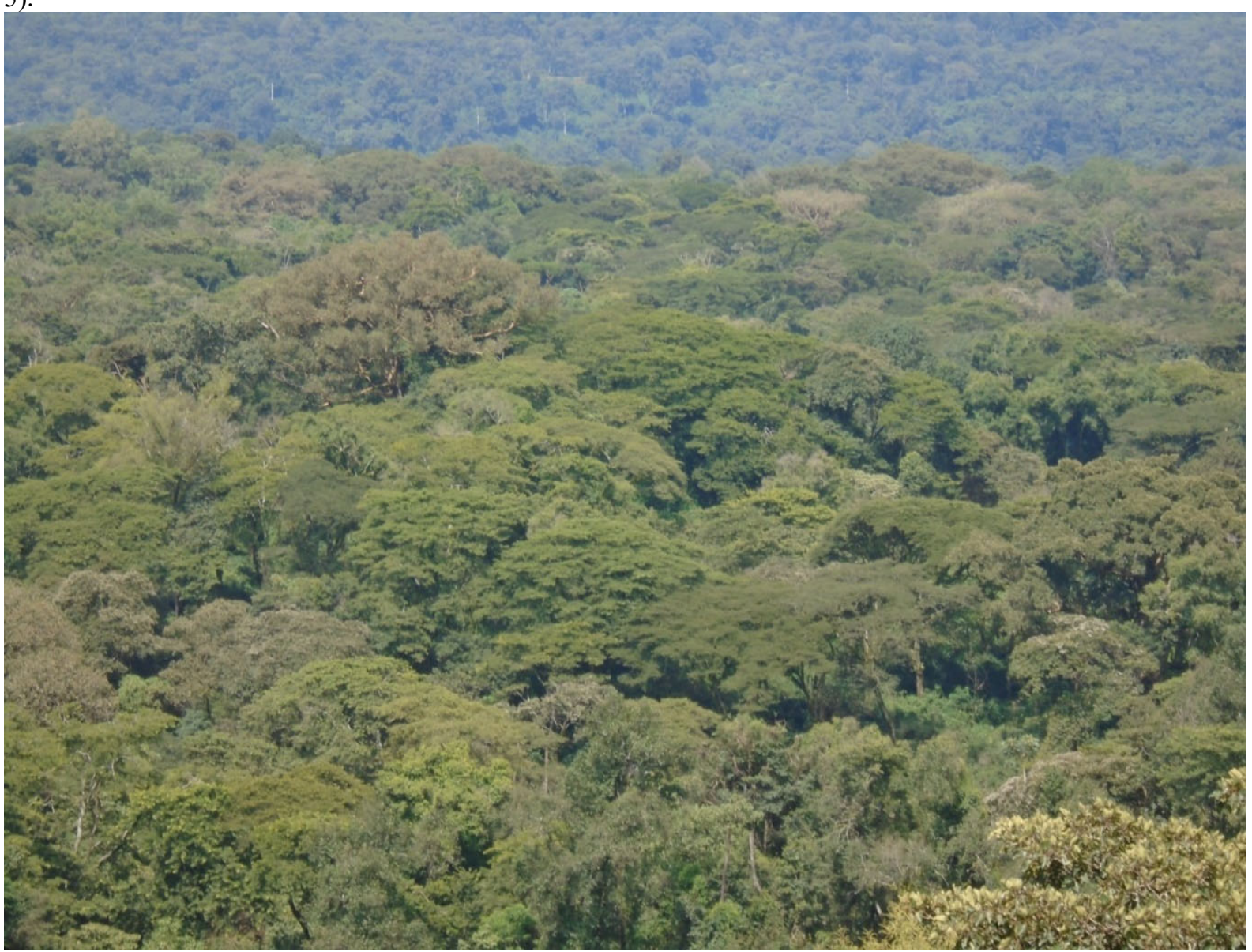

Figure5: Forest of Haro Aba Diko Controlled Hunting area.

\section{Bettere Water falls}

Now a days waterfall is the most interesting natural tourism destinations, in the context of our country,using water fall as tourism resource is not well done. Bettere Water fall that is found in chora woreda is one of the most important tourist destinations if promoted and tourist facilities are fulfilled. According to focus group discussions this water fall is consist of natural caves that is the habitat for various attractive bird species and the community also practicing bee keeping activities in this cave (fig6). 

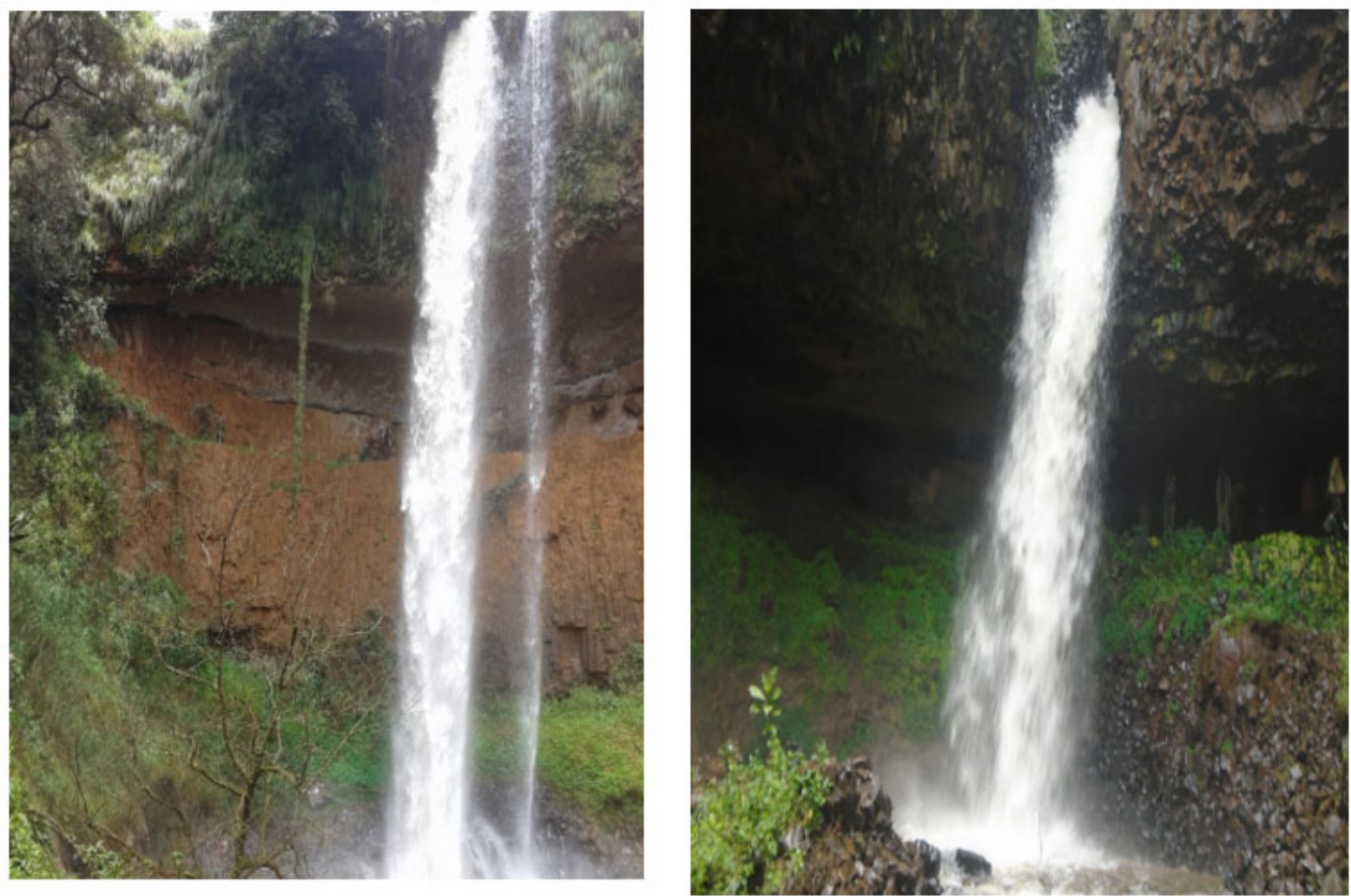

Figure6: Betteeree/cooraa/ water falls

\section{Dabena Waterfall.}

This is one of potential tourism destinations that was found near the Bunno Bedelle zone. The information obtained from respondents indicated that Dabena River is potential of fish species which could be source of income for local community around it (figure). This shows that if ecotourism is started in the area, community could benefit in various way.However due to poor management of the destinations the community nearby the destinations not gained the more benefit from this river as well as waterfall(fig7). 


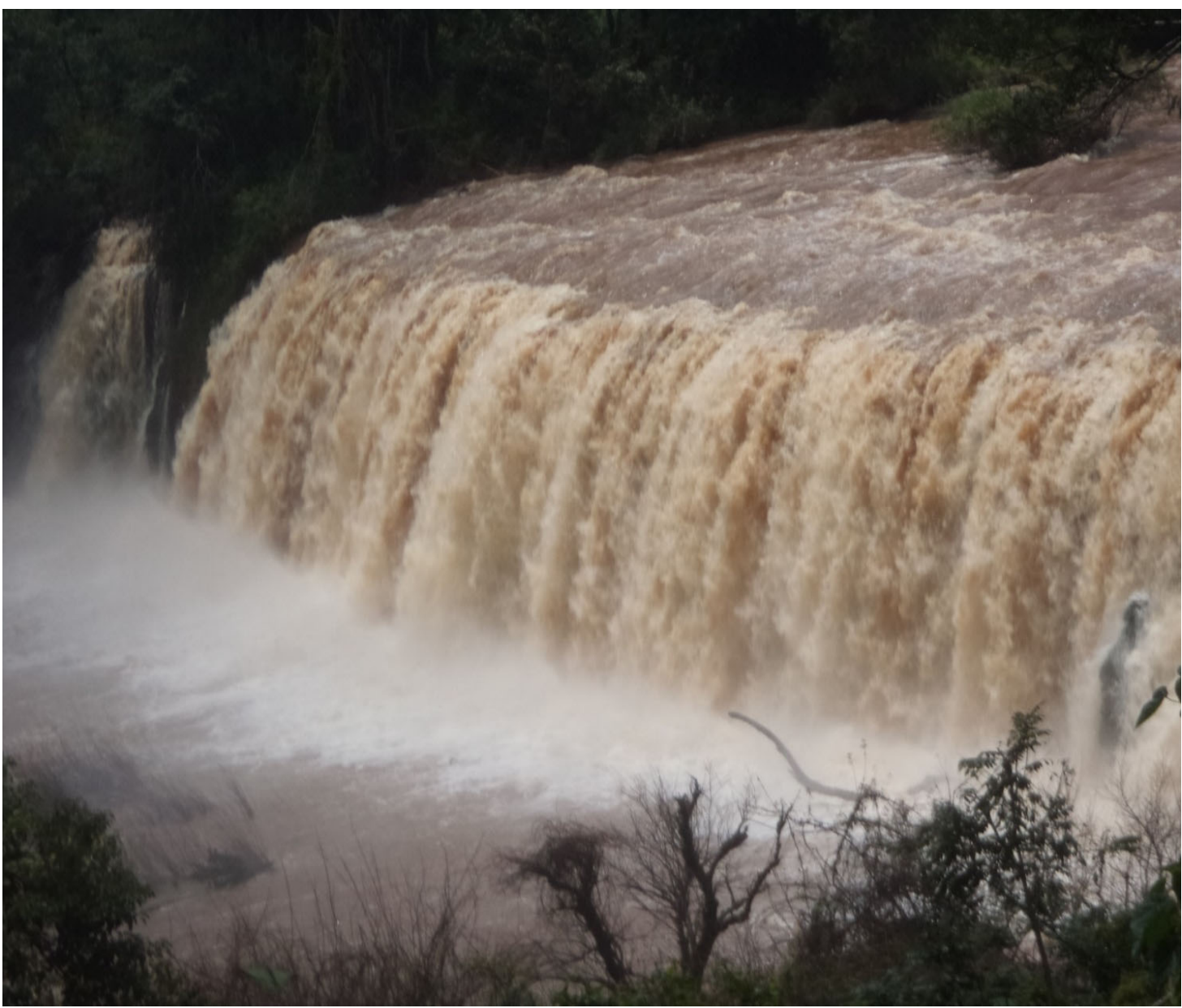

Figure7: Dabena waterfall

\section{Dhambacha stone and simbir water fall}

Dhambacha stone and the water fall of simbir that are found in Borecha woreda are one of the natural tourist attractions destinations. According to focus group discussions and interview with sample respondents this water fall is attractive in nature and it is a pleasure place for them during their leisure time.

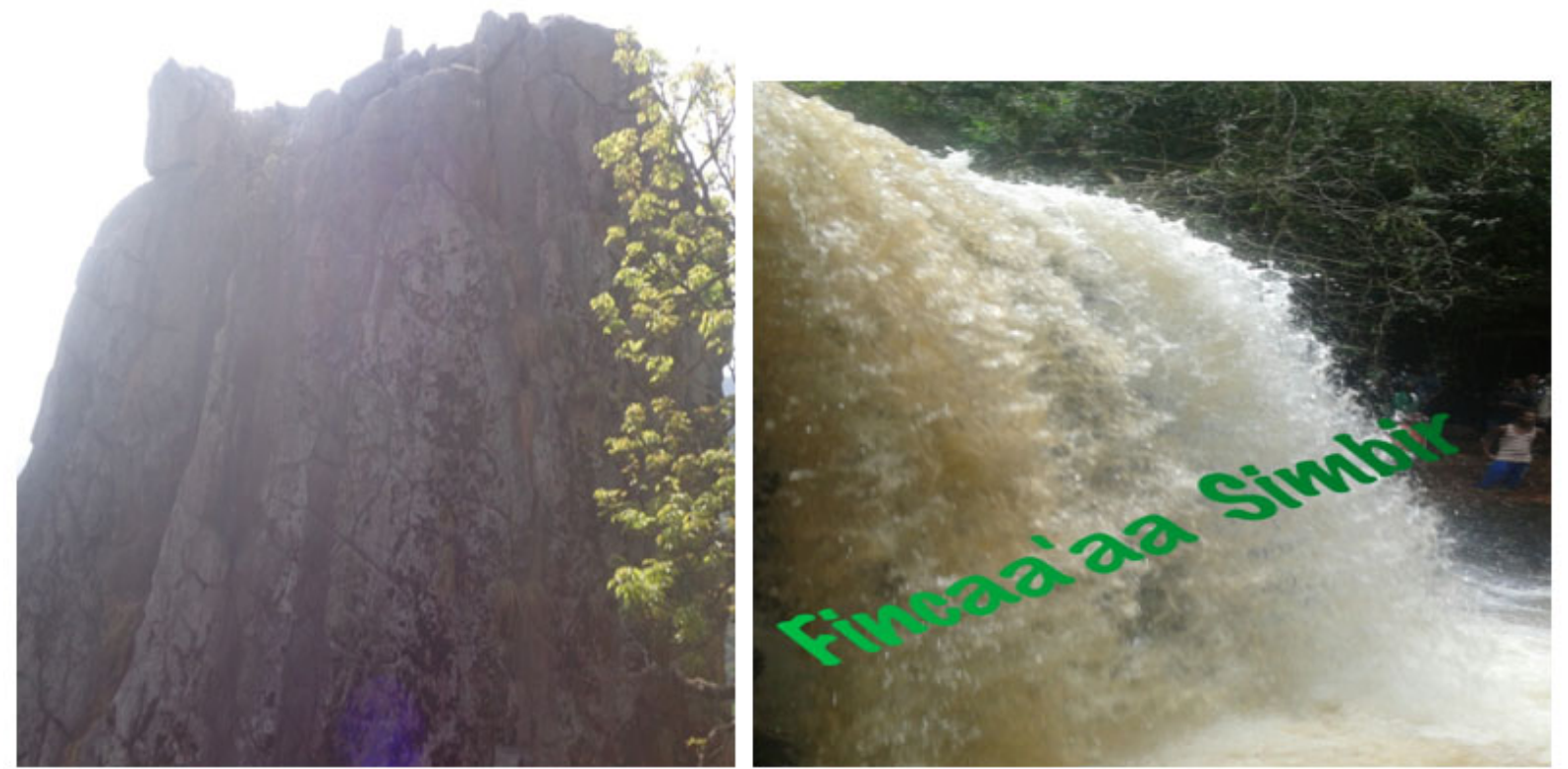

Figure8: Simbir water fall and Dhambacha stone (Borecha Woreda) 


\subsection{Cultural attractions of Bunno Bedelle Zone}

In addition to the above mentioned potential natural tourism resource Bunno Bedelle zone is also endowed with historical and cultural resources. The following are identified as cultural tourism resources of the area.

\subsubsection{Cultural Food and Drink of Bunno Bedelle zone oromo ethnic groups}

According to respondents' interview and community discussion, by Oromo ethnic group that found in Bunno Bedelle zone practice both tangible and intangible cultural practices, cultural food and Drink is among tangible cultural resources that makes Bunno Bedelle zone an ideal place for developing diversified kind of ecotourism products for the sustainable benefit of the local community. During study period of time the researcher identified various cultural food and drinks these are:Buna Qalaa, Anchootee, Marqaa. Caccabsa, Maqinoo (irra Dibaa), Keenetoo, Bookaa, Daadhii (Figure 9).

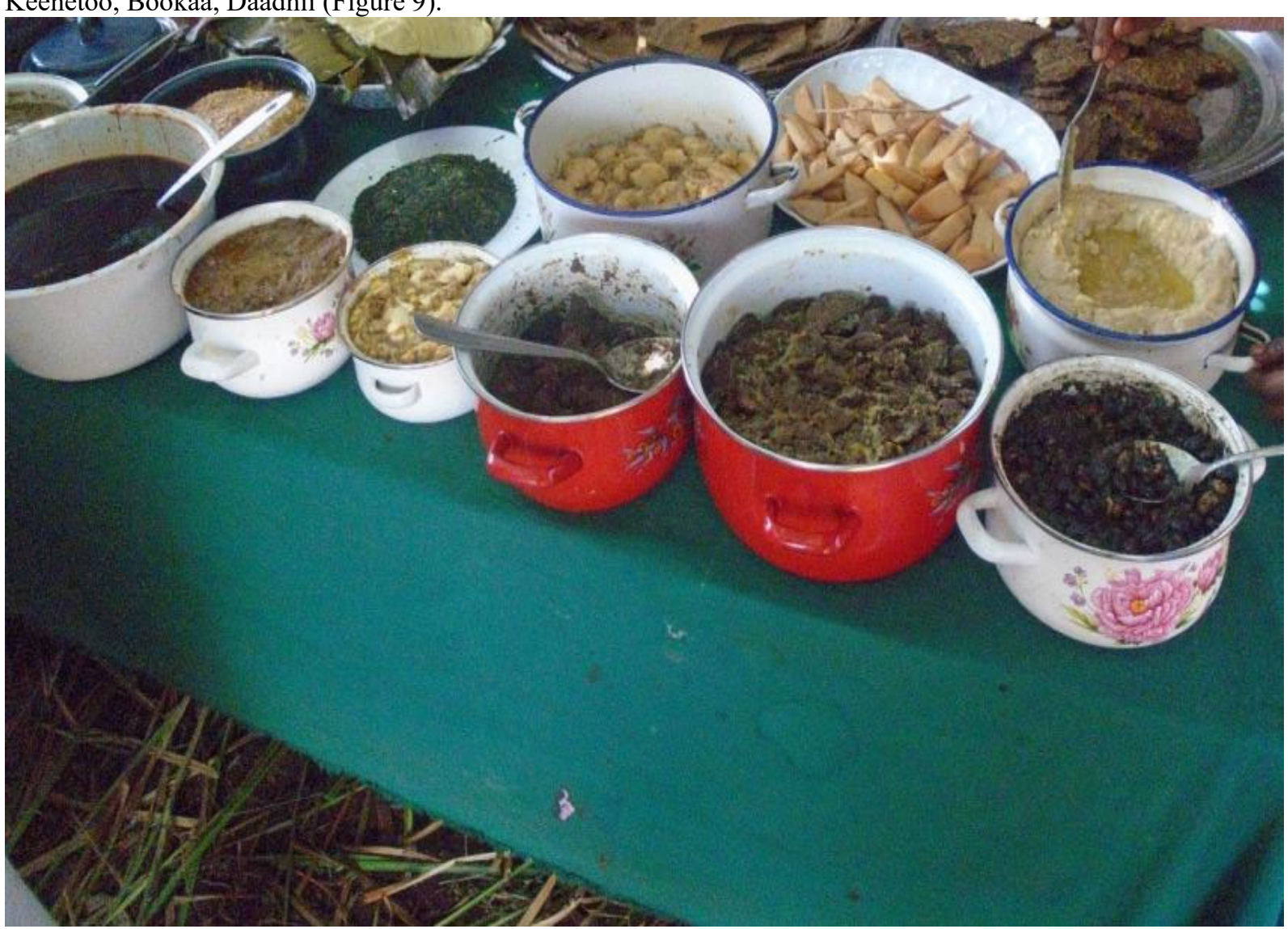

Figure9: Cultural food and Drinks of Bunno Bedelle zone of oromo Ethnic group

\section{Coffee Ceremony}

According to community discussions and key informants interview, drinking coffee is an essential part of daily life among them. It plays a vital role in socio-economic, political, cultural and religious life of the people. Making coffee involves roasting coffee beans and boiling water this helps to discuss on issues like culture, work ethics, peace, health, education and other societal issues. The traditional coffee ceremony plays great role in creating opportunity to deal with conflicts of the community members by way of traditional conflict resolution mechanism called Jaarsummaa. The ceremony itself reflects that sharing the ceremony means the neighbors are in peace with each other. The guests of the ceremony also wish peace to the family who arranged the ceremony saying, 'bunaa fi nagaa hin dhabinaa' meaning 'let coffee and peace be upon you (Figure). 


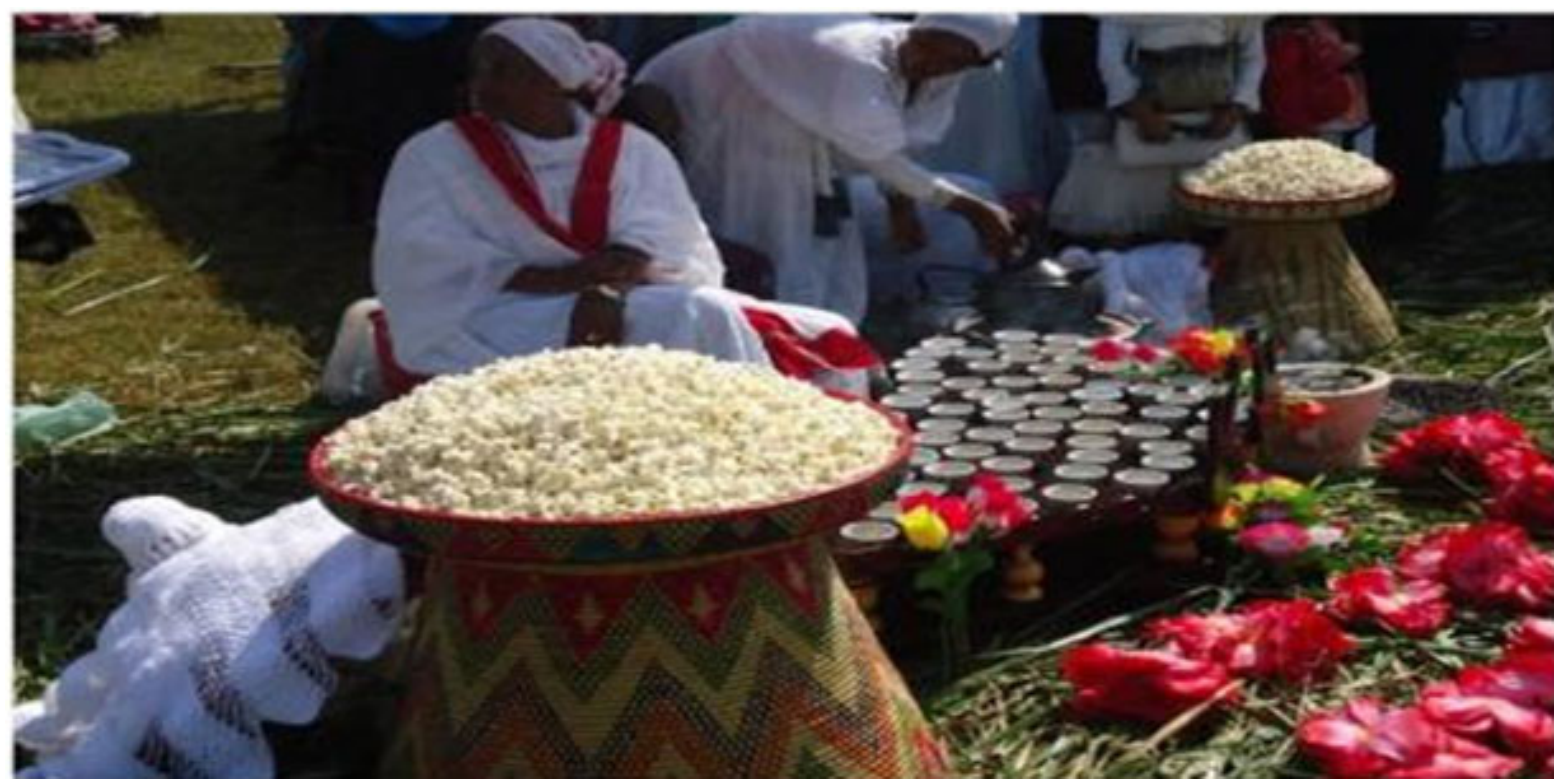

Figure:10 Coffee ceremony by the oromo ethnic group of Bunno Bedelle zone.
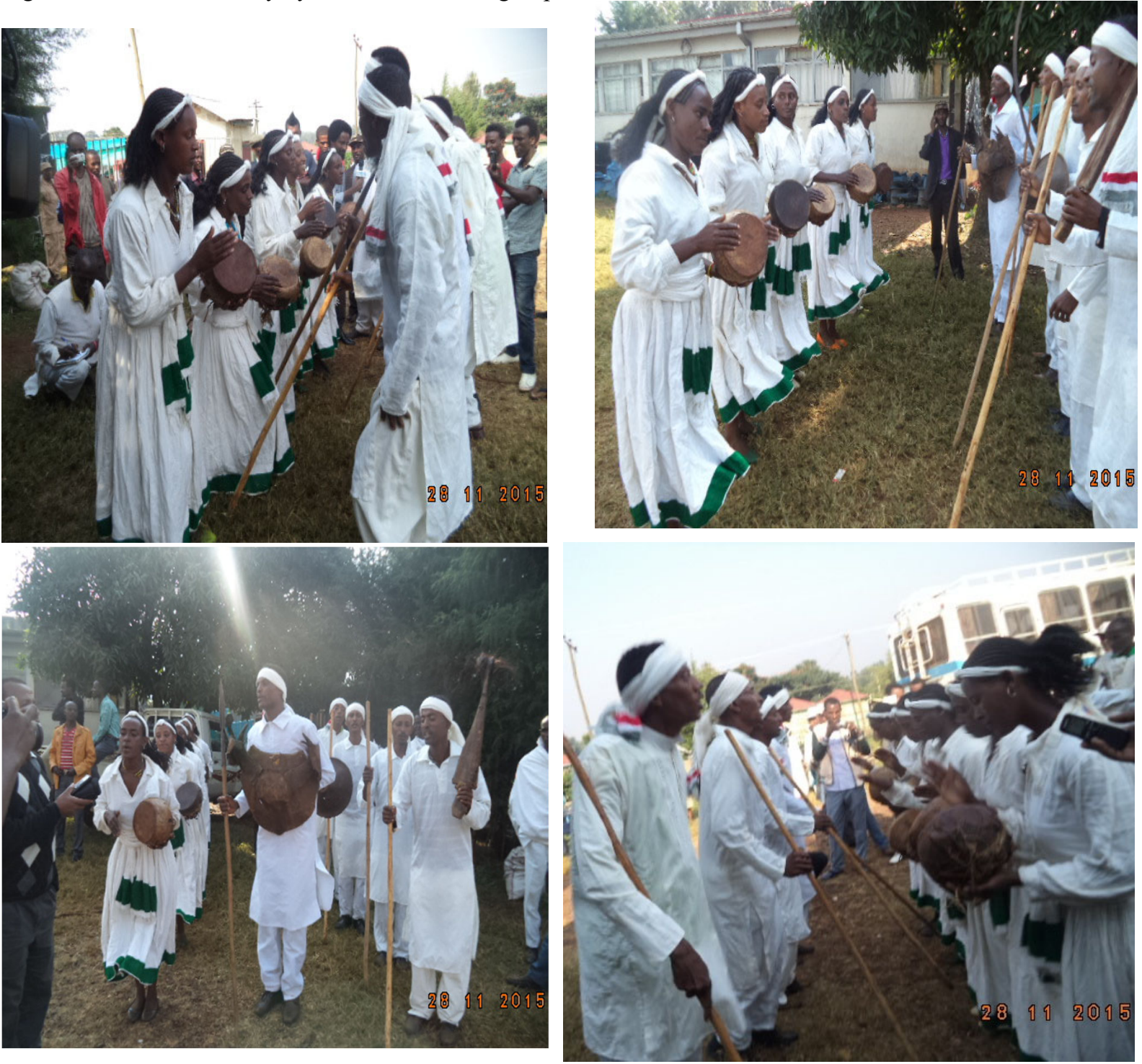

Figure11: Cultural danse and dressing style of oromo ethnic group found in Bunno Bedelle Zone 


\section{industrii a adaa}
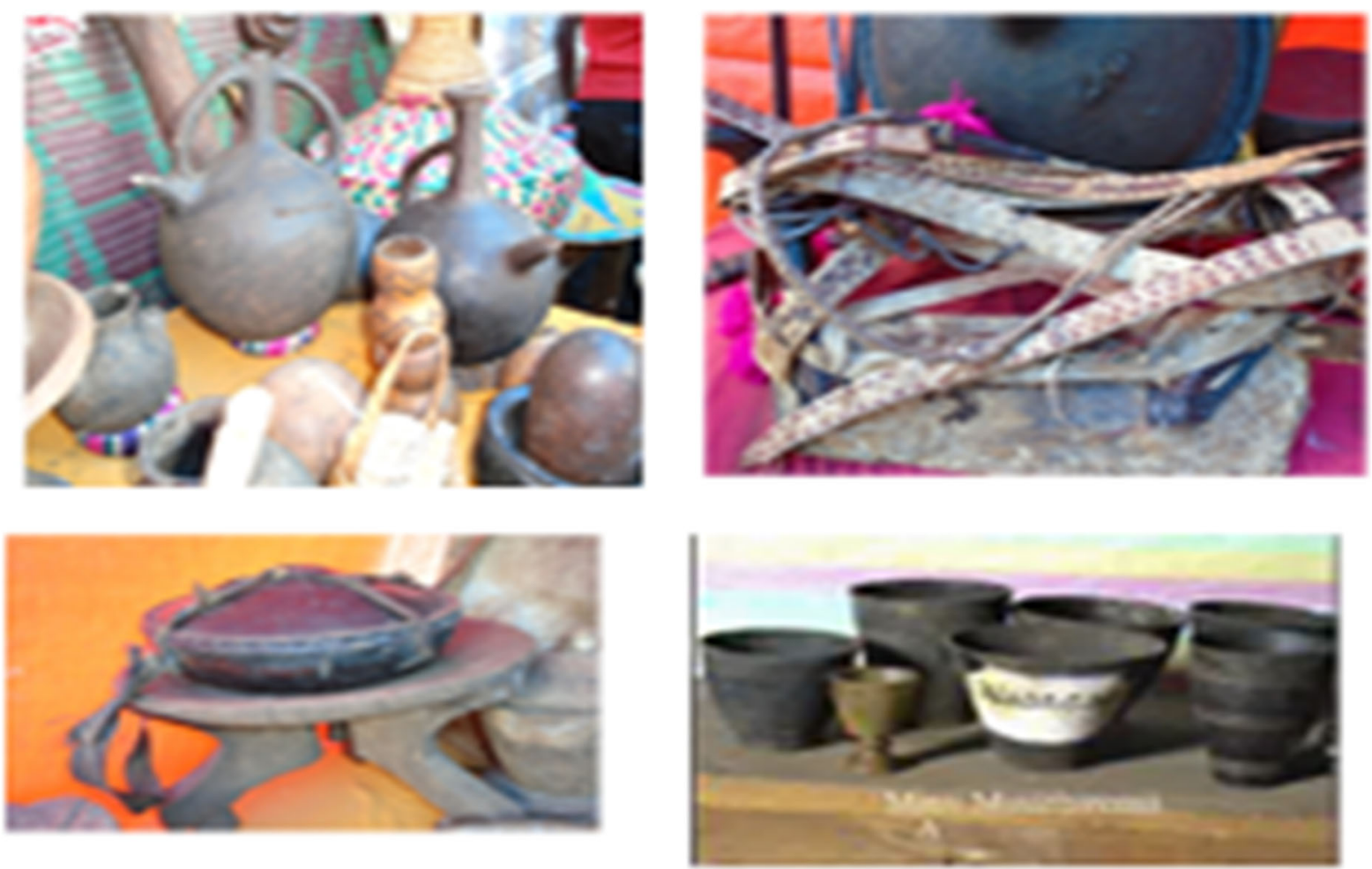

Figure12: Cultural artifacts of Bunno Bedelle Zone oromo Ethnic group Source:(Bunno Bedelle cultural and tourism office.)

The above figures (11\&12) illustrate some of the cultural features that exist in Bunno Bedelle zone. Given their shared similar culture with other localities in the zone, the local communities can also inevitably utilize these cultural features if ecotourism is developed in their area. With regard to the benefits of ecotourism as related to cultural tourism in Bunno Bedelle zone, the participants in the FGD and interview sessions pointed out that local community can get a lot of benefit. The mentioned potential cultural features in Bunno Bedelle zone of oromo ethnic group are performing cultural dances, showing hair styles, cultural food preparation system, traditional home construction system the local communities can also open souvenir shop to sell traditional material and cloth. Hence, the presences of such kind of cultural features in Bunno Bedelle zone are opportunities for the development of ecotourism.

\subsection{Challenges faced to develop ecotourism at destinations of Bunno Bedelle Zone}

The results of collected information indicated that Bunno Bedelle Zone has huge potential for ecotourism development. However there was challenges that limit to initiate and develop, this are lack of awareness and limited participation of community in decision making and management activities, limitation in community capacity building in tourism concept, lack of expertise in the area to develop community based ecotourism and lack of basic infrastructure like absence of adequate transport facilities, communication facilities, health care facilities ,accommodation service, lodge service that are essential for visitor and host community are some of the challenges that hinders the development of ecotourism in the Area s(Figure 12). 


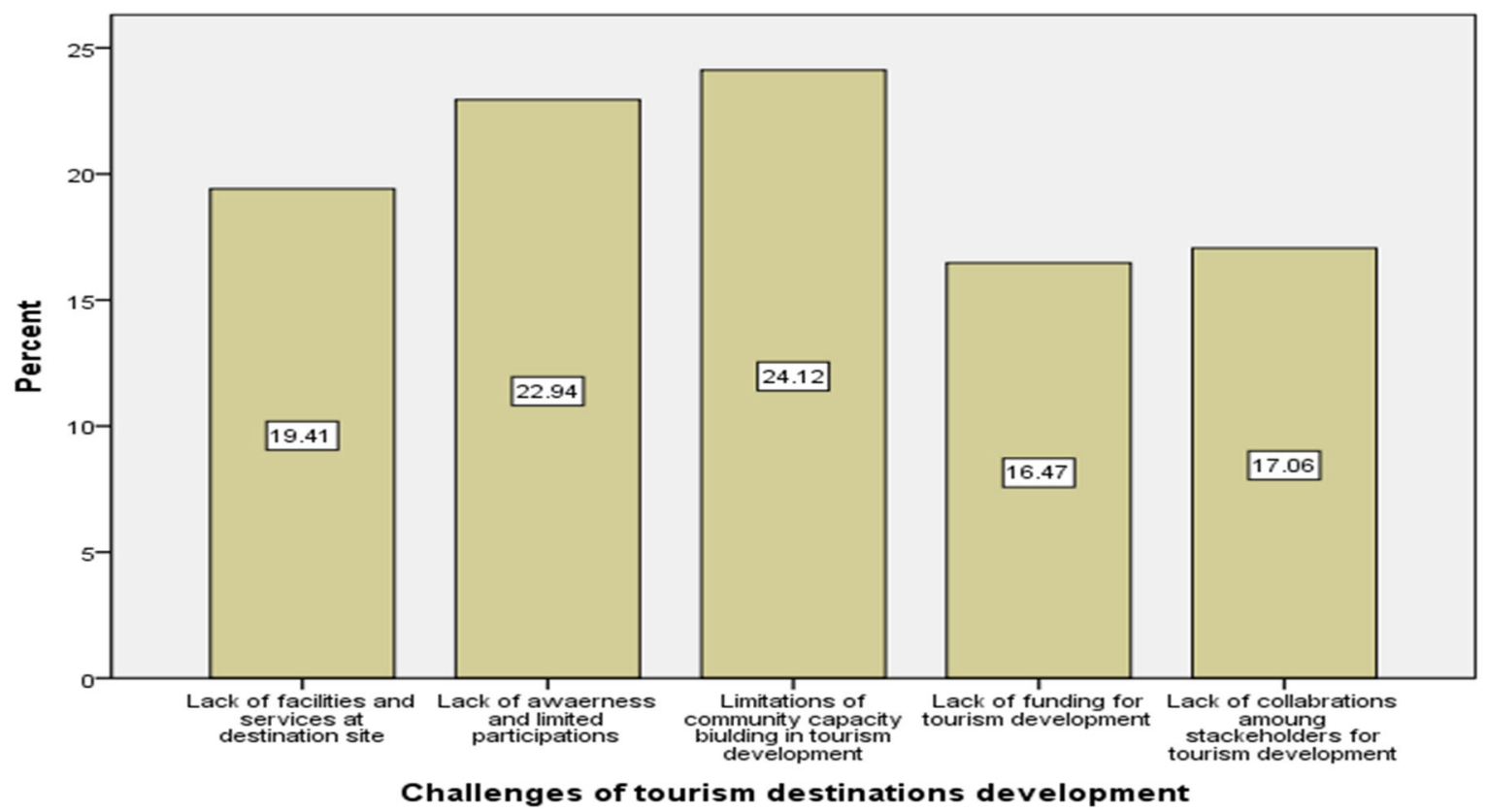

Figure13: Responses of the respondent to the different Challenges to develop ecotourism.

The above figure (13) showed, (24.2\%) of respondents mentioned that there is limitations of community capacity buildings $22.9 \%$ of respondents mentioned lack of awareness and limited participations of community as obstacles to promote tourism destinations of the area. This indicates that Lack of knowledge and awareness can affect the participations of community in every aspect of conservations activity. Given that community participation is an essential element for ecotourism development, lack of awareness and participations of community can affect the establishment and development of ecotourism. (19.41\%) of sampled respondents replied that lack of facilities and service destination site as another challenges that leads community towards resource degradations. The participants during FGD confirmed that there is no enough infrastructure and accommodation around the tourism destination site. Unless this infrastructure related problem is solved, it is challenging to successfully develop ecotourism in the area. It is in line with the studies of Demeke and Verma (2014) and Alemayehu (2011) identified limited transportation and accommodation facilities as a challenge for ecotourism in their study area. $17.06 \%$ of sampled respondents mentioned that, the regional, zonal and woreda culture and tourism office coordination is very weak.

There is no strong link and communication of bottom up or up down communication between each office. Tourism is a multi-sectoral activity that requires different stakeholders to participate. Hence, its success is greatly determined by the role every stakeholder pertains to play. A key to the success of ecotourism is the formation of strong partnerships so that the multiple goals of conservation and equitable development can be met

\subsubsection{Limited Tourism Research and Development}

Limited research concerning tourism development is another challenge of the study areas to promote potential tourism resources of the destinations. There was no more research conducted in Bunno Bedelle zone concerning tourism in general and ecotourism in particular. This indicated that the study area was not promoted and need further study to promote the potentials of the area as well as to facilitate the establishment of community based ecotourism for the week of minimizing the degradations of resource and to provide income to the country in general and improvements of the livelihood of local community surrounding the area in particular.

Therefore, to overcome such obstacles an urgent solution is needed through facilitating the mechanisms that facilitate the promotions of tourism destination site and participate community in every aspect of conservation activity.

\section{CONCLUSIONS AND RECOMMENDATIONS}

This research attempts to examine the potentials and challenges of promoting tourism destinations of, Bunno Beddele zone, south western Ethiopia. The result of the study showed that the area has huge atractive natural and cultural potential resource needed for ecotourism development. These includes Dabena and Didessa river diversity of fauna such as African Buffalo (Syncerus caffer), Bush Pig,( Potamochoerus larvatus) Black and white monkey(Colobus guereza), Common bush Buck(Tragelaphus scriptus), Water Buck(Kobus ellipsiprymnus ) Plain Zebra (Equus quagga,) Blue monkey (Cercopiticus mitis) and Rivers that is source of fish species, attractive forest found in the study area, and cultural resource of the area like dressing style of local community,delicious cultural food and drink of local community are valuable opportunities that empower development of ecotourism, 
However having these potential resource ecotourism development in the destinations is constrained by

$\checkmark \quad$ Lack of community knowledge about ecotourism

$\checkmark$ Limitations in community capacity building from government organizations

$\checkmark \quad$ Lack of community social infrastructures that had led local community to destructions potential resource of study area.

$\checkmark \quad$ Lack of promotions of the study area potential resource for tourism

$\checkmark$ Lack of cooperation's among community and governmental and private organizations to discuss on constraints and opportunity of the study area.

To establish the ecotourism and minimizing the challenges of tourist destinations, the following recommendations were forwarded.

* It has to have broader awareness creation program for the wider communities towards the tourism business and its impacts on their lives by providing adequate trainings.

$\$$ To ensure community-based ecotourism establishment in the study area, local communities must undergo various capability-building programs. This in turn, enables the communities to provide them with skills which are needed to manage the tourism

* Local community social infrastructural service should be provided in order to reduce community dependence on natural resource.

* A further investigation is needed to identify and promote potential resource of the destinations .

\section{Acknowledgements}

My greatest and deepest appreciation goes to study village communities for their kind support in supporting this study. Thanks, are also owed to all individuals and organizations who directly or indirectly participated in this research and for the journal which waived the fees.

\section{REFERENCES}

Ambelu, G. (2011). Practices, Challenges and Opportunities of Community Based Ecotourism Development in Meket Woreda North Wollo; Unpublished Thesis Addis Ababa University

Ayalew, S. (2009). Historical Development of Travel and Tourism in Ethiopia. Addis Ababa: Commercial Printing Enterprise.

Baker, N. (2008). Sustainable wetland resource utilization of Sango Bay through ecotourism development. African J. Environ. Sci. and Technol., 2(10): 326-335.

Belsky, J. (1999). Misrepresenting communities: The politics of community-based rural ecotourism in gales point manatee, Belize. Rural Sociology, 64 (4), 641-666.

Berhanu, K. (2013). Opportunities and Challenges for Wildlife Conservation and Ecotourism Development of Alatish National Park; Northwest Ethiopia; unpublished thesis, University of Gondar.

Berhanu, W. (2003). The role of Tourism in the economic development of local communities in Ethiopia: A cased study of Gerealta \&Axum areas of Tigray administrative region. Master from www.irrob.org/ectouris_in_ethiopia.

Bires, Z. (2014). Challenges and Prospects of Community Based Ecotourism Development In Lake Zengena, BanjaWoreda, Awi Nationility Administration; unpublished thesis, Addis Ababa University.

Birtukan,A. (2018). Atinkut pitfalls of tourism development in ethiopia: a case of bahir dar town and its surroundings, a historical perspective, Vol.6, No.1, pp.11-28.

Choi, H.C. and Murray, I. (2010). Residents Attitudes toward Sustainable Community Tourism, Journal of Sustainable Tourism 18 (4): 575-594

Demeke, A. \& Ashok, V. (2013). Local attitude towards environmental conservation and ecotourism in BMNP, Journal of Environmental Science and Water Resources, 2(8)

Denman, R. (2001). Guidelines for community-based ecotourism Development: World Wide Fund for Nature, Gland, Switzerland.

Eshetie, W. (2012). Potentials, Challenges and Opportunities for Community Based Ecotourism Development at Borena Sayint National Park; South Wello, Unpublished thesis University of Gondar.

Fariborz, A., Ma'rof, R. and Sarjit G. (2009). Dimensions of Community Capacity Building: A review of its Implications in Tourism Development. Journal of American Science. 5(8).

Faulkner, B. and Tideswell, C. (2010). A Framework for Monitoring Community Impacts of Tourism, Journal of Sustainable Tourism 5(1): 3-28.

Gabeyehu A, G. (2011). Practices, Challenges and Opportunities of Community Based Ecotourism Development in Meket Woreda North Wollo; Unpublished Thesis Addis Ababa University

Ghosh, B. (2005). Tourism and Travel Management. New Delhi: Vikas Publishing House Pty. Ltd.

Habte, J. (2014, 2015). Pilot socio-economic analysis (SIA) of the planned protected area of the Dabena Didessa River Valley, south Western Oromia Region, Ethiopia and Community Education to Conserve Wildlife in 
the Didessa River Valley, south Western Ethiopia -through the use of Local resource.

Hatton, M.J. (1999). Community-Based Tourism in the Asia-Pacific. Toronto, Ontario, Canada. Available at URL: http:// www.community-tourism.org, accessed on (03,011,2017).0

IUCN (1996). World conservation, Special issue on collaborative management, NO-2 .

LDMA, (2010). Annual progress report, Livestock Development and Marketing Agency, (LDMA). Ilu Aba Bora Zone Department of Agriculture. Mettu, Ethiopia.

Martin, D. (2008) Ecotourism in Ethiopia. Retrieved from www.mondediplo.com on November15,2017.

Michael K (2003). "Ecotourism, environmental preservation and conflicts over natural resources "Horizontes Antropológicos, 20:185-203.

Minca, C. and M. Linda. (2000). Ecotourism on the Edge: the Case of Corcovado National Park, Costa Rica. In X. Font and J. Tribe (Eds), Forest Tourism and Recreation. Case studies in environmental management 103-126.

Ministry of Culture and Tourism. (2009). Federal Democratic Republic of Ethiopia Tourism Development Policy, Addis Ababa.

Mitchell, J. and Muckosy, P. (2008). A Misguided Quest: Community-Based Tourism in Latin America. London: Overseas Development Institute.

MOCT, 2006). Ministry of Culture and Tourism of Ethiopia.Unpublished: Tourism statistics bulletin No.8.

MOCT. (2010). Ministry of Culture and Tourism: Tourism Statistics Bulletin. Addis Ababa: AB GET Printing Press.

Mulugeta,A.(2011).Community based ecotourism as a tool for biodiversity conservations and sustainable development .Semien mountain national park,Addis abab university,

Neto, F. (2002). Sustainable tourism, environmental protection and natural resource management: paradise on Earth? Retrieved from http://www.mtnforum.org .Accessed on October 15,2017.

Roselyne, N. O. (2010). Tourism Development in Africa: Focus on Poverty Alleviation. The Journal of Tourism and Peace Research. Retrieved from https:/www.scribd.com/document/93996175/Tourism-Developmentin-Africa [05 February 2017]

Sewnet, T. (2017). Challenges and Opportunities for Community Based Ecotourism Development in Ethiopia. African Journal of Hospitality, Tourism and Leisure, Volume 6 (3)

Sharpley, R. \& Telfer, D. (2002). Tourism and Development: Concepts and Issues. Clevedon, Channel View.

Sharpley, R. and Telfer, D. (2008). Tourism and Development in the Developing World. Abingdon: Routledge

Shirlow, P. and Murtagh, B. (2004). Capacity-Building, Representation and Intra Community Conflict. Urban Studies, 41:1, 57- 70.

Sintayehu, A. (2013). Tourism Potentials and Community-Based Ecotourism Development, a Case of Choke Mountain and its Environs, Ethiopia, Journal of Hospitality and Management Tourism,6,(4).

Temesgen, K. (2014). The Tourism Industry in Ethiopia. Mekelle University, Ethiopia

Teresa, D.(2015).Development of community based ecotourism in Wenchi Crater Lake, Ethiopia: Challenges and prospects, Journal of Hospitality and Management Tourism, Vol. 6(4), pp. 39-46

The International Ecotourism Society (2012). Ecotourism development; Retrieved from website http//www.ecotourism.org, 27th september, 2017.

United Nations (2001). UNEP manual for the international year of ecotourism. pp. 1-18. Retrieved from www.uneptie.org/tourism/home/html: United Nations Environment Program.

UNWTO. (2013). Report of the World Tourism Organization to the United Nations Secretary. General Action for the Least Developed Countries. Retrieved from http://www.unwto.org/pub/right.htm.Accessed date May, 2015.

Wearing, S. (2001). Exploring Socio-cultural Impacts on Local Communities. In David B. Weaver (Ed), Encyclopedia of Ecotourism. CABI Publishing. New York:pp.395-410

World Bank (2006) Ethiopia in Makeda's Footsteps: towards a strategy for pro-poor tourism development. World Bank Report No. 38420-ET

WTO, (2002c). Enhancing the economic benefits of tourism for local communities and poverty alleviation WTO, Madrid, Spain. 